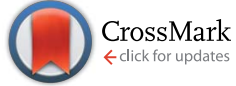

Cite this: RSC Adv., 2015, 5, 30833

Received 20th February 2015 Accepted 24th March 2015

DOI: $10.1039 / \mathrm{c} 5 \mathrm{ra03249k}$

www.rsc.org/advances

\section{Catalyst free production of partial glycerides: acetone as solvent $\uparrow$}

\author{
Alchris Woo Go, ${ }^{a}$ Sylviana Sutanto, ${ }^{a}$ Suryadi Ismadji ${ }^{b}$ and Yi-Hsu Ju*a
}

Glycerolysis of sunflower oil was studied using acetone as the solvent. Reactions were carried out at 200 to $250{ }^{\circ} \mathrm{C}$ without the need of conventional catalyst. The use of acetone in glycerolysis of oil allowed the reaction to be carried out at $250{ }^{\circ} \mathrm{C}$ and $1.8 \mathrm{MPa}$, resulting in a product that comprises $4.5 \%$ solketal, $5.8 \%$ FFA, 49.2\% MG, 33.5\% DG and 7\% TG in 2 h. The important parameters investigated in this study were acetone addition, stirring and reactor loading. This new approach in the synthesis of partial glycerides (monoglycerides and diglycerides) avoids the use of chemical catalyst, thus avoiding unnecessary wastewater production. The partial glycerides produced may be utilized in may areas of food and pharmaceutical industries. Moreover the use of acetone as solvent allows the process to be carried out at lower operating pressures compared to other non-catalytic glycerolysis and at the same time co-produces solketal, having a wide application in fuels, pharmaceuticals and chemical synthesis.

\section{Introduction}

The emulsifying properties of monoacylglycerides (MG) and their derivatives have long been studied and utilized in food, pharmaceutical, cosmetic and lubricant industries. ${ }^{1}$ Its use as surfactant and emulsifier mainly resides in its structural conformation, which comprises an aliphatic lipophilic chain (fatty acid) and two hydroxyl groups in the hydrophilic ends. ${ }^{2}$ The industrial production of MG is through glycerolysis of triglycerides (TG) with glycerol. The glycerolysis process is typically carried out at high temperatures $\left(220-260^{\circ} \mathrm{C}\right)$, with an alkali catalyst, pressurized under nitrogen atmosphere. ${ }^{3,4}$ At the end of the reaction, the catalyst is immediately neutralized and the reaction mixture rapidly cooled to minimize reverse reaction. ${ }^{4-6}$ To minimize production cost, utilization of crude glycerol in base-catalyzed biodiesel production has been studied, which allows the reuse of the catalyst. ${ }^{6}$ A major drawback of these processes is the use of alkaline catalyst and the presence of free fatty acids (FFA), which would result in the formation of metallic soap, leading to flavor and odor problems when blended in food products. To avoid such problems the use of supercritical carbon dioxide media (SC-CDM) has been studied. Temelli et $a l .{ }^{5}$ found that a maximum MG content of $49.2 \%$ could be achieved at $250{ }^{\circ} \mathrm{C}, 20.7 \mathrm{MPa}$ and a glycerol/oil molar ratio of 25 with the presence of $4 \%$ water in $4 \mathrm{~h}$. This method

${ }^{a}$ Department of Chemical Engineering, National Taiwan University of Science and Technology, 43, Keelung Rd., Sec. 4, Taipei 106-07, Taiwan. E-mail: yhju@mail. ntust.edu.tw

${ }^{b}$ Department of Chemical Engineering, Widya Mandala Surabaya Catholic University, Kalijudan 37, Surabaya 60114, Indonesia

$\dagger$ Electronic supplementary information (ESI) available. See DOI: $10.1039 / \mathrm{c} 5 \mathrm{ra} 03249 \mathrm{k}$ was successfully employed to various oils (soybean, peanut, cottonseed, corn and canola) with the final product containing 41-49\% MG and the rest mostly diacylglycerides (DG) with some unreacted TG (10-16\%) and FFA (9-14\%). ${ }^{5}$ Moquin et al. ${ }^{1}$ carried out the glycerolysis of canola oil at $250{ }^{\circ} \mathrm{C}$ and $10 \mathrm{MPa}$ nitrogen, using a glycerol to oil molar ratio of 43 and $8 \%$ water. After $9 \mathrm{~h}$ of reaction, the product contains 66-71\% MG, 13-15\% DG, $13-17 \%$ FFA and $1 \%$ TG. Moreover no significant differences in product composition were found between reaction carried out using SC-CDM and that under nitrogen atmosphere at $10 \mathrm{MPa}^{1}$ Both processes utilized water under subcritical condition to partially hydrolyze TG and simultaneously carried out glycerolysis by adding glycerol in excess of its stoichiometric requirement.

An alternative way to prepare partial glycerides (PG) is through (trans)esterification of FFA and their alkyl esters with pure or crude glycerol in the presence of an alkaline catalyst. ${ }^{4,7} \mathrm{~A}$ major advantage of this process is its low temperature (135-210 ${ }^{\circ} \mathrm{C}$ ), while the drawback is the need to continuously remove the methanol and water produced during the reaction through continuous vacuum and/or striping using nitrogen to favor the forward reaction..$^{7-9}$ The environmental friendly lipase-catalyzed glycerolysis of oil requires considerably lower reaction temperature $\left(40-70{ }^{\circ} \mathrm{C}\right),{ }^{3,10,11}$ but may take hours to days depending on enzyme loading and the reaction system employed, which may be solvent free multi-phase or single-phase solvent. In a solvent free system, MG could reach $30 \%$ in $2 \mathrm{~h}$ at an enzyme loading of 7.5\%. ${ }^{10}$ While $70 \%$ MG could be achieved when tert-butyl alcohol was used as the solvent but requiring a catalyst loading of over $20 \% .{ }^{11}$ Glycerol is a hygroscopic material, which makes the formation of FFA in the product unavoidable. FFA in the glycerolysis of oil typically ranges from 5 to $16 \%$. 
Each process has its own advantages and disadvantages. To the best of the authors' knowledge, this study is the first to explore the use of acetone under sub or supercritical condition as solvent for the glycerolysis of oil without the use of conventional catalyst.

\section{Materials and methods}

\subsection{Materials}

Refined sunflower oil was obtained from a local supermarket in Taipei. Standards of fatty acid (FA), acylglycerides (AG) such as monoolein, diolein and triolein and fatty acid methyl esters (FAMEs) were purchased from Supelco (Bellfonte, PA). All solvents and reagents used were either high performance liquid chromatography (HPLC) or analytical reagent grade, obtained from commercial sources. Acetone used in the experiment was kept in a bottle with $4 \mathrm{~A}(8-12 \mathrm{mesh})$ molecular sieves overnight prior to use in order to remove moisture.

\subsection{Glycerolysis of TG (sunflower oil)}

Predetermined amounts of sunflower oil, glycerol and acetone were added into a glass chamber and placed in a high-pressure reactor (Fig. S1†). The reactor was sealed and purged with nitrogen to remove air in the headspace. The reactor is equipped with an external electric heater and a magnetic stirrer. Temperature in the reactor was controlled to within $\pm 2{ }^{\circ} \mathrm{C}$. The reactor is also equipped with a removable aluminum spacer on top of the glass chamber (Fig. S1 $\dagger$ ) for adjusting the reactors effective volume $\left(V_{\mathrm{r}}\right)$.

The reaction was carried out with constant stirring $(\sim 300$ rpm) at $250{ }^{\circ} \mathrm{C}$. Heating rate of the reactor was kept at $\sim 5{ }^{\circ} \mathrm{C}$ $\min ^{-1}$ with a heating time of 40 to $45 \mathrm{~min}$. The moment the reactor reached the desired temperature, the reaction time was taken as time zero. After the reaction, the reactor was rapidly cooled and product in the reactor was collected at room temperature.

The collected product containing PGs was transferred to a separation funnel and $20 \mathrm{~mL} 5 \% \mathrm{NaCl}$ solution was added to remove the unreacted glycerol. The solution was allowed to clarify. The upper PG-rich phase was withdrawn and the funnel was rinsed twice, each with $20 \mathrm{~mL} n$-hexane, to recover the products. The pooled organic phases were dried using a rotary evaporator (BUCHI Labortechnik AG in Flawil, Switzerland) operated at $70{ }^{\circ} \mathrm{C}$ and $13.3 \mathrm{kPa}$. The recovered product was weighed and analyzed for FFA and AG contents using HTGC. Results of the reaction were evaluated in terms of PG yield and TG conversion, values reported are average results from duplicate experimental trials.

PG yield is defined as the mass of MG or DG $\left(M_{\mathrm{PG}}\right)$ produced per mass of oil $\left(M_{\text {Oil }}\right)$ used in the reaction. This was calculated using eqn (1), where $A_{\mathrm{PG}}$ is the area calculated from the GC analysis and $f_{\mathrm{c}}$ is the external calibration factor (slope of the calibration curve) while $C_{\mathrm{s}}$ and $V_{\mathrm{s}}$ are the concentrations and volumes of the samples prepared and injected to the GC for analysis, respectively. Conversion of TG was calculated using eqn (2).

$$
\begin{gathered}
\text { PG yield }(\%)=\frac{M_{\mathrm{PG}}}{M_{\mathrm{oil}}} \times 100 \%=\frac{M_{\text {product }}}{M_{\mathrm{oil}}} \times \frac{\sum A_{\mathrm{PG}} f_{\mathrm{c}}}{C_{\mathrm{s}} V_{\mathrm{s}}} \times 100 \% \\
\text { Conversion }(\%)=\left(1-\frac{\mathrm{TG}_{\text {final }}}{\mathrm{TG}_{\text {initial }}}\right) \times 100 \%
\end{gathered}
$$

\subsection{Gas chromatography analysis}

Chromatographic analyses were carried out according to the method described previously. ${ }^{12}$ A $20 \mathrm{mg}$ aliquots from the collected sample was dissolved in ethyl acetate and filtered through a $0.2 \mu \mathrm{m}$ PTFE hydrophobic membrane to remove moisture. From this prepared solution, a $1.0 \mu \mathrm{L}$ sample was injected into a HTGC for analysis. External calibration curve was generated using $0.2-20 \mathrm{mg}$ of a pure standard dissolved in ethyl acetate.

Qualitative and quantitative analyses of glycerides (MG, DG and TG) and FFAs in each sample were performed using a Shimadzu GC2010 (Kyoto, Japan) equipped with a splitinjector and a flame ionization detector. Separation was carried out on a ZB-5HT (5\% phenyl)-methylpolysiloxane nonpolar column $(15 \mathrm{~m} \times 0.32 \mathrm{~mm}$ i.d., $0.1 \mathrm{~mm}$ film thickness) (Zebron Phenomenex, Torrence, CA). Both injector and detector temperatures were set at $370{ }^{\circ} \mathrm{C}$. The column temperature was programmed to increase at a rate of $15.0^{\circ} \mathrm{C}$ $\min ^{-1}$ from $80{ }^{\circ} \mathrm{C}$ to $365{ }^{\circ} \mathrm{C}$ and held at $365{ }^{\circ} \mathrm{C}$ for $48 \mathrm{~s}$. Nitrogen was used as the carrier gas with a linear velocity of $30 \mathrm{~cm} \mathrm{~s}^{-1}$ at $80{ }^{\circ} \mathrm{C}$. Data analyses were carried out by the software "GC Solution version 2.3", Shimadzu.

\section{Results and discussion}

Table S1† shows the characteristic and composition of the sunflower oil used in this study. The mean molecular weights of fatty acid and TG calculated according to the fatty acid composition were 279.56 and 876.65 , respectively and are similar to those reported in literature (279.45 and 876.54, respectively). ${ }^{13}$ The following experiments were all designed based on these molecular weights.

\subsection{Acetone as solvent}

The use of acetone as solvent for low-temperature chemical glycerolysis catalyzed by $\mathrm{NaOH}$ was first carried out by Zhong et al. ${ }^{14}$ in 2010 mainly to produce DGs. For the reactions carried out in this study, the temperatures were well over the critical temperature of acetone $\left(235.05{ }^{\circ} \mathrm{C}\right)$, thus enough acetone was loaded into the reactor to ensure it was under supercritical state. With the maximum available reactor volume of $134 \mathrm{~mL}, \sim 47 \mathrm{~mL}$ acetone was required in order to satisfy the critical volume $\left(209 \mathrm{~mL} \mathrm{~mol}^{-1}\right)$ and inducing a pressure of at least $4.7 \mathrm{MPa}$ placing acetone under supercritical state.

The reaction was initiated by loading the reactor to $80 \%$ of its maximum capacity using an oil to glycerol molar ratio of $1: 5$ and $50 \mathrm{~mL}$ acetone. After $1 \mathrm{~h}$ of reaction at $250^{\circ} \mathrm{C}$, a TG 
conversion of $23 \%$ was observed. Reaction was also carried out without the addition of acetone which resulted in a much lower TG conversion (9.2\%). To understand the effect of acetone on TG conversion, the amount of acetone added was varied from 0 to $50 \mathrm{~mL}$ and the results are presented in Fig. 1 . The total reactor loading was fixed at $80 \%$ in order to minimize the head space available (Fig. 2), a smaller head space implies a smaller volume for acetone vapor to occupy and thus ensuring most acetone was in the liquid state during heating up and reaction.

Interestingly the addition of acetone even below the required amount to reach critical state $(\sim 47 \mathrm{~mL})$ also resulted in significant increases in conversion, with a maximum conversion of $42.2 \%$ at an acetone loading of $30 \mathrm{~mL}$. It was noted that all reactor pressures in reactions carried out at various acetone loadings were below the critical pressure of acetone (4.7 MPa). Pressure in the reactor increased with increasing acetone loading and approached 3.5 $\mathrm{MPa}$ as acetone loading was increased to $50 \mathrm{~mL}$. This was possibly due to the fact that acetone was in a mixture at $250{ }^{\circ} \mathrm{C}$ which mainly comprised sunflower oil $\left(T_{\mathrm{c}}=698.3{ }^{\circ} \mathrm{C} ; P_{\mathrm{c}}=0.34 \mathrm{MPa}\right)$ with negligible vapor pressure and glycerol $\left(T_{\mathrm{c}}=395.9{ }^{\circ} \mathrm{C} ; P_{\mathrm{c}}=5.4 \mathrm{MPa}\right)$ with a vapor pressure of $0.49 \mathrm{MPa}$.

Fig. 2 is a schematic drawing that shows, before the start of reaction, how much space each reaction component occupies at a reactor loading of $80 \%$ and a oil to glycerol molar ratio of $1: 5$. As acetone amount is increased, the amounts of glycerol and oil that can be loaded to the reactor decreases resulting in the dilution of glycerol and oil in the reaction mixture thus decreasing the reaction rate.
To confirm the dilution effect caused by excess acetone, a different experimental approach was employed. This time constant amounts of sunflower oil (38 g) and glycerol $(20 \mathrm{~g})$, equivalent to a molar ratio of $1: 5$, was employed. In Fig. 3 the same trend as that in Fig. 1 can be observed. Surprisingly after $1 \mathrm{~h}$ of reaction, the optimum conversion increased dramatically from $42.2 \%$ (Fig. 1) to $76.6 \%$ (Fig. 3). At fixed loadings of oil (38 $\mathrm{g}$ ) and glycerol (20 g) as shown in Fig. 2F, reducing the acetone added results in an increase in reactor head space. This allowed more acetone to exist as vapor, leaving behind a more concentrated mixture of reactant resulting in improved conversion. This can be supported by the final system pressure attained. By comparing Fig. 2 and 3, a bigger head space resulted in a lower pressure obtained by the system at the same amount of acetone loaded.

It is also worth noting that by comparing Fig. 1 and 3, reaction with a lower overall loading resulted in a higher conversion even without the addition of acetone. A TG conversion of $9.2 \%$ was obtained at a reactor loading of $80 \%$ while TG conversion increased to $36.5 \%$ at a reactor loading of $\sim 40 \%$. This could be attributed to the quality of mixing during the reaction. Since the reactor used in this study was only equipped with a magnetic stirrer, stirring can only be set at a specific mixing power but not at a constant stirring speed. At lower reactor loading, the reaction mixture was more vigorously stirred, resulting in higher conversion. It was also observed that the addition of acetone allowed better mixing as it lowers down the mixture viscosity, which indirectly lowered the mixing intensity required to promote good mixing between reactants, resulting in better conversion.

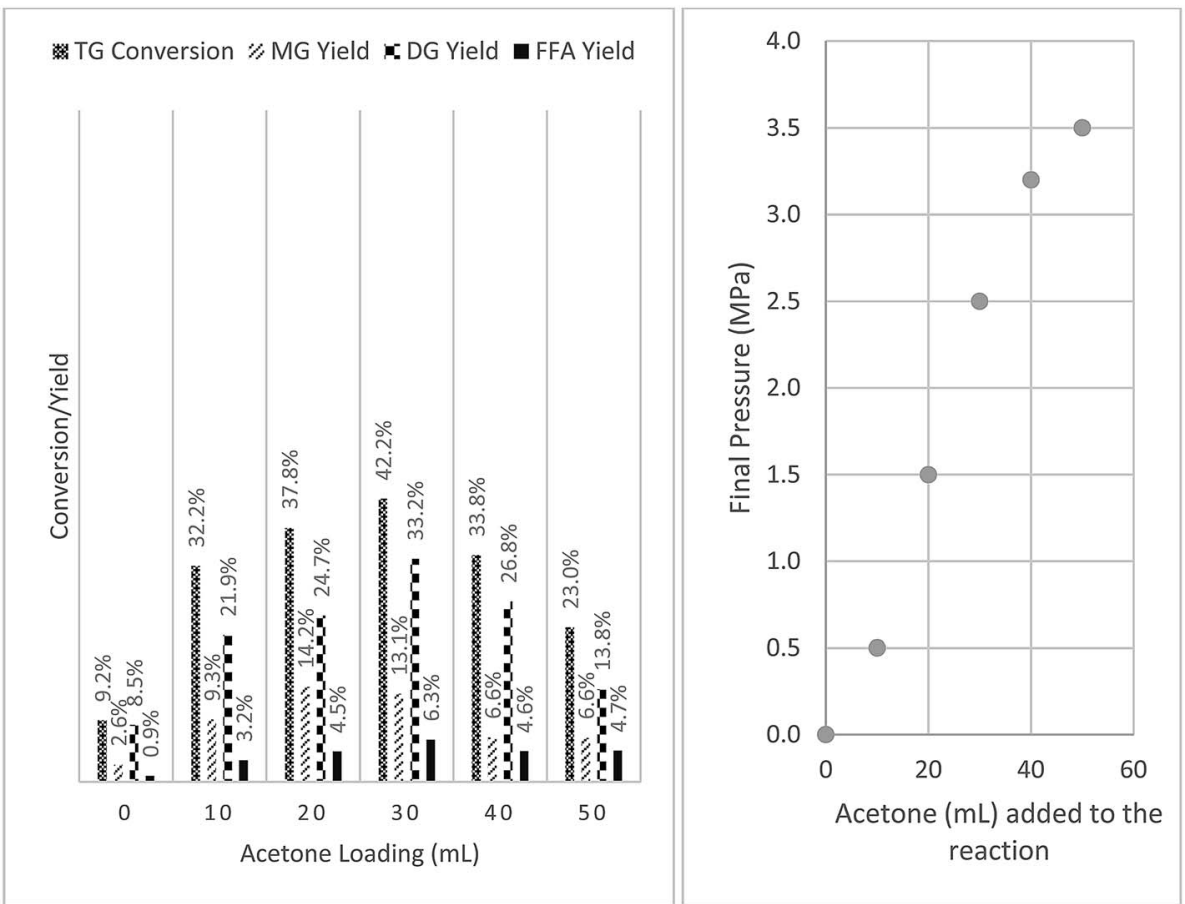

Fig. 1 Effects of acetone addition on glycerolysis of sunflower oil at $250{ }^{\circ} \mathrm{C}$ ( $P=0$ to $3.5 \mathrm{MPa}$ ) for $1 \mathrm{~h}$ with constant stirring, $80 \%$ reactor loading, oil to glycerol mole ratio $=1: 5$. 


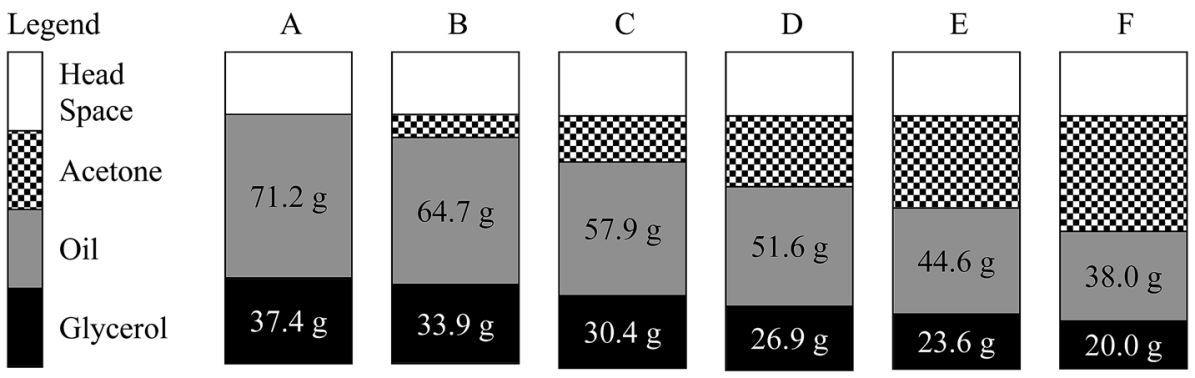

Fig. 2 Schematic drawing showing the space occupied by the reacting components at different acetone loading but at fixed reactor loading $(80 \%)$ and fixed oil to glycerol mole ratio (1: 5$)$.

\subsection{Effect of reaction time}

The glycerolysis reaction proceeded slowly before reaching 250 ${ }^{\circ} \mathrm{C}$ which required 40 to $45 \mathrm{~min}$. A TG conversion of $\sim 11 \%$ was observed as can be seen in Fig. 4. Similar to those reported in literatures, ${ }^{\mathbf{1 , 5}}$ for non-catalytic glycerolysis of oils DG, MG as well as FFA were simultaneously produced (Fig. S2 $\dagger$ ). This is due to the presence of trace amount of water which resulted in hydrolysis of AGs. The presence of trace water $(\sim 1 \%)$ in the glycerol added to the reaction mixture is difficult to avoid due to its hydroscopic nature. Analysis of the product showed the existence of solketal $(4.47 \%$ in Fig. S3 $\dagger$ ) after a reaction time of 2 $\mathrm{h}$, which was a byproduct of ketalyzation reaction between glycerol and acetone and in the process water was also produced..$^{15}$ After $2 \mathrm{~h}$ of reaction the final product constituted of 4.5\% solketal, 5.8\% FFA, 49.2\% MG, 33.5\% DG and 7\% TG. A typical GC chromatogram is shown in Fig. S3. $\dagger$

\subsection{Effects of stirring and reactor loading}

Acetone was chosen as the solvent due to its capacity to dissolve oils despite of it being a hydrophilic and polar solvent with a dielectric constant of 20.7 at $25{ }^{\circ} \mathrm{C}$. Acetone with a $\log P$ value of -0.24 implies that although it is hydrophilic but still has the capability of dissolving in hydrophobic substances like oil and at the same time soluble in hydrophilic substances like glycerol. Unfortunately the solubility of glycerol in acetone is fairly low at room temperature. At room temperature, after the addition of acetone into oil and glycerol mixture distinct 2 layers were still observed. Although improved solubility is expected at higher temperatures, it is still imperative to carry out stirring for nonhomogeneous reactions to improve contact between reactants.

As mentioned earlier, stirring with a laboratory magnetic stirrer can only maintain the stirring power and not the mixing intensity which is also affected by the amount of material being

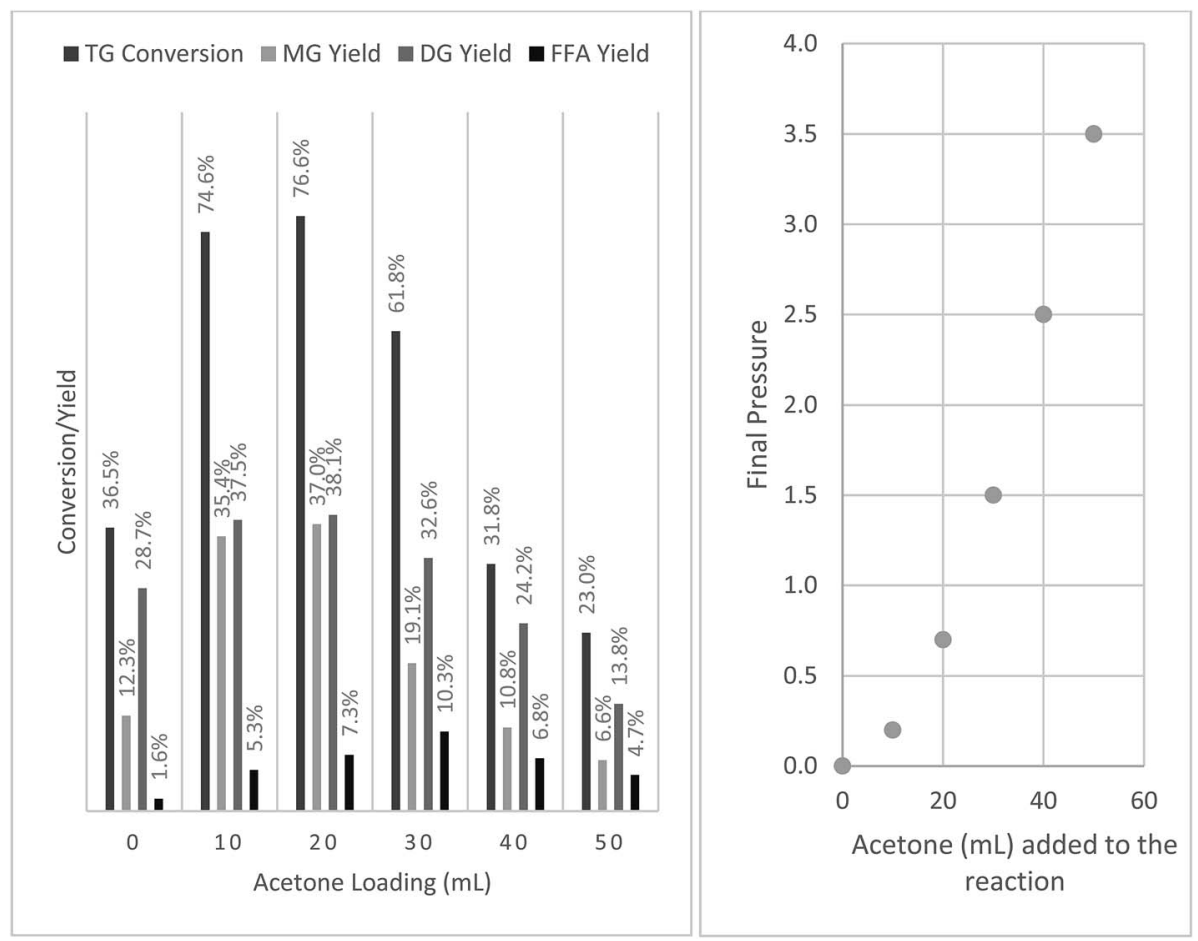

Fig. 3 Effects of acetone addition on glycerolysis of sunflower oil at $250^{\circ} \mathrm{C}(P=0$ to $3.5 \mathrm{MPa}$ ) for $1 \mathrm{~h}$ with constant stirring, fixed oil loading ( $38 \mathrm{~g}$ ) and fixed glycerol loading $(20 \mathrm{~g})$ which is equal to an oil to glycerol mole ratio of $1: 5$. 


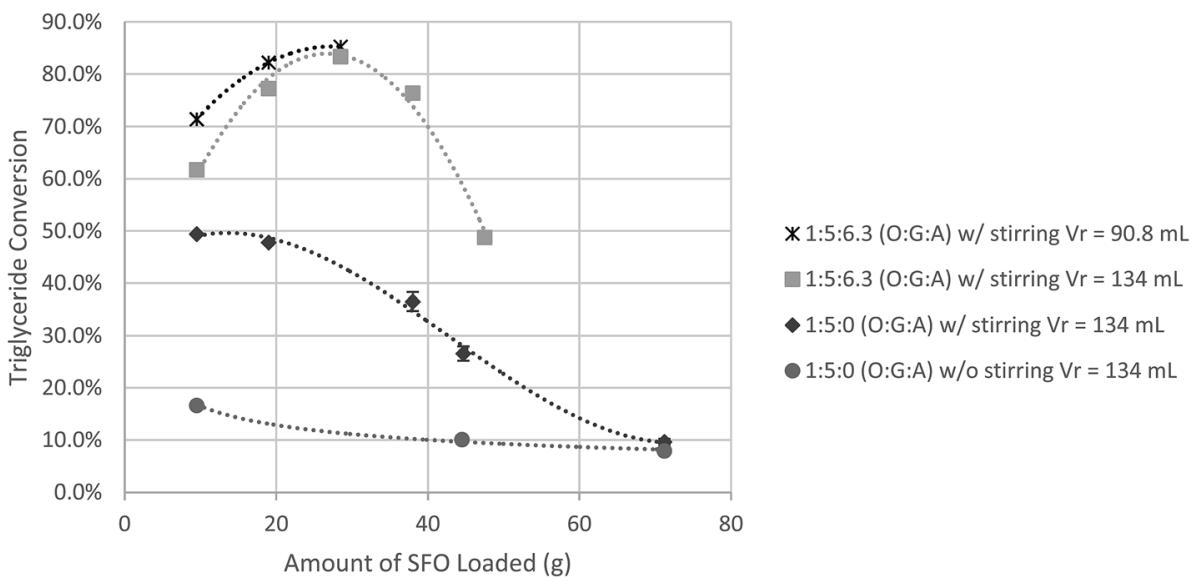

Fig. 4 Effects of stirring and oil loading on TG conversion in glycerolysis of sunflower oil at $250{ }^{\circ} \mathrm{C}$. Fixed oil to glycerol molar ratio ( 1 : 5), reaction time $1 \mathrm{~h}$. O : G:A = molar ratio of oil, glycerol and acetone. $V_{r}$ is the effective reactor volume.

mixed. Thus the effect of stirring was investigated together with the effect of overall loading and the results are summarized in Fig. 4.

As can be seen in Fig. 4, low TG conversions ( $10 \%)$ were obtained when a high sunflower oil loading of $72 \mathrm{~g}$ was used resulting in an overall reactor loading of $80 \%$ without the addition of acetone. It was found that stirring had negligible effect. When less amount of soybean oil was used the amount of glycerol was also reduced since reactions were carried out at oil to glycerol molar ratio of $1: 5$. As loading was reduced, TG conversion for both stirred and unstirred reactions increased. For unstirred reaction, as loading was decreased the interface area between glycerol and oil remained the same, thus when the amount of oil was decreased a higher conversion was also achieved. For stirred reactions large increase in TG conversion was observed as oil loading was decreased due to the more rigorous mixing at a fixed stirring power. A maximum TG conversion of $50 \%$ was obtained for the case of stirred reaction compared to that of the unstirred reactions $(<20 \%)$.

With the addition of acetone, TG conversion increased significantly. A maximum TG conversion of $>80 \%$ can be achieved at an oil loading of $28.5 \mathrm{~g}$, a glycerol loading of $15 \mathrm{~g}$ and with addition of $15 \mathrm{~mL}$ acetone. Under this condition, the overall loading of the reaction is $\sim 43 \%$. At higher overall loadings lower TG conversion was achieved as a result of too much acetone resulting in dilution and/or poor mixing due to the presence of more glycerol, which impeded the stirring due to its high viscosity. Further Increase in loading for reactions with acetone beyond an oil loading of $47.5 \mathrm{~g}$ was not possible since an overall reactor loading of $80 \%$ was maintained ( $\sim 98 \%$ of the glass reactor capacity). Compared to reaction without acetone, the addition of acetone lowered the mixtures viscosity and allowed better mixing thus resulting in higher conversion.

As overall loading was decreased at a fixed molar ratio (oil : glycerol : acetone $=1: 5: 6.3$ ), the available head space was increased allowing more acetone to vaporize. This again suggests that too much acetone in the system resulted in dilution of the reactants concentration. Another possibility is the competitive reaction when more acetone is present, consuming the available glycerol for ketalyzation. At overall loading below the optimum, too little acetone remained as liquid to aid the reaction and resulting in lower conversion.

To prove that a larger head space (lower overall loading) resulted in lower yield due to vaporization of acetone, a spacer was installed into the reactor to reduce the reactors effective volume from $134 \mathrm{~mL}$ to $90.8 \mathrm{~mL}$. As shown in Fig. 4, maintaining the same loading at a reduced reactor volume resulted in higher conversion, which suggests that the head space in the reactor should be kept as low as possible to induce enough pressure allowing more acetone to exist in the liquid phase.

\subsection{Effects of reaction temperature}

Most studies on non-catalytic glycerolysis of oil were carried out at $250{ }^{\circ} \mathrm{C}$. In this study reaction temperature was varied from 200 to $260^{\circ} \mathrm{C}$. Even at a reaction time of $1 \mathrm{~h}$ no TG conversion was observed at $200^{\circ} \mathrm{C}$ which agrees with the results of Temelli et al. ${ }^{5} \mathrm{TG}$ conversion was very low at temperatures below $230{ }^{\circ} \mathrm{C}$ as can be seen in Fig. 5 .

Above $235{ }^{\circ} \mathrm{C}$, TG conversion increased rapidly with increasing temperature. The same trend was observed in the product composition shown in Fig. 5. Except for the lower DG produced at $260{ }^{\circ} \mathrm{C}$ probably due to conversion to MG, others remained similar to those at $250{ }^{\circ} \mathrm{C}$. Solketal was also detected and its concentration increased rapidly with increasing temperature.

In the study of ketalyzation of glycerol to form soketal in supercritical acetone, Royon et al. ${ }^{15}$ observed that acetone acted as an acid catalyst at temperatures higher than its critical temperature. This was possibly through the keto-enol tautomerism of acetone releasing an alpha hydrogen which acted as catalyst in glycerol.

\subsection{Process comparison and evaluation}

To make easier comparison (Table 1) of the results obtained in this study with those reported in literatures, product 


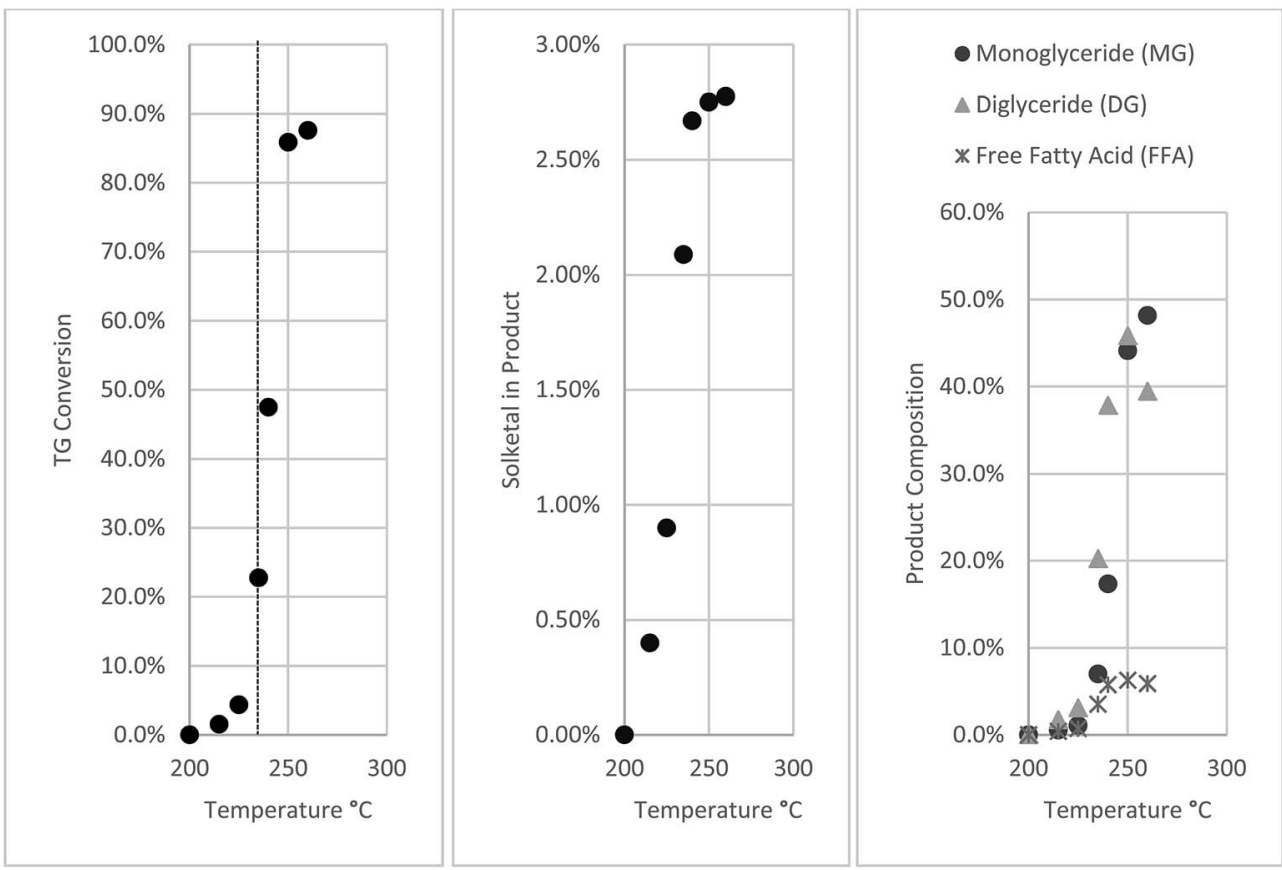

Fig. 5 Effect of reaction temperature on TG conversion and product composition in glycerolysis of sunflower oil. Reaction time $1 \mathrm{~h}$ with constant stirring, fixed oil loading (28.5 g), glycerol loading $(15 \mathrm{~g})$ and acetone loading $(15 \mathrm{~mL})$. Molar ratio of oil to glycerol $=1: 5$.

compositions are expressed in relative amounts excluding solketal. Except for the U.S. patent $2,474,740,{ }^{16}$ where the process was carried out continuously in a counter current column, for studies not using base or enzyme as catalyst a batch reactor was often used. The use of a counter current flow system provides the advantage of inherent mixing between reactants. Moquin et al. ${ }^{\mathbf{1} 17}$ used a batch reactor with an external magnetic stirrer at a mixing rate of $250 \pm 30 \mathrm{rpm}$, while Temelli et al. ${ }^{5}$ utilized an autoclave with a paddle type agitator at $1040 \mathrm{rpm}$. These studies required at least $4 \mathrm{~h}$ to reduce TG to 10 to $16 \%$ even with vigorous stirring. ${ }^{5}$ To obtain higher MG formation reactions were extended up to $9 \mathrm{~h}$ with $66-71 \mathrm{~mol} \% \mathrm{MG}$ in the product. ${ }^{1}$ Moreover in these studies high molar ratios of glycerol to oil (25 to 34) were used ${ }^{\mathbf{1}, \mathbf{5}, 17}$ which are much higher than the ratio of 5 used in this study. Large excess glycerol might have caused the slower reaction rates observed in their studies.

With the aid of acetone as demonstrated in this study, lower amount of glycerol is required. Together with proper mixing and overall loading, high TG conversion (>85\%) could be attained in $1 \mathrm{~h}$. Product produced has similar composition to

Table 1 Comparison with other non-catalytic glycerolysis of edible oil

\begin{tabular}{|c|c|c|c|c|c|c|c|}
\hline Oil type & Co-solvent/additive & $\mathrm{O}: \mathrm{G}$ ratio & Time, h & Pressure, $\mathrm{MPa}$ & Temp., ${ }^{\circ} \mathrm{C}$ & Product profile, wt\% (mol\%) & Reference \\
\hline Coconut & $\begin{array}{l}5-10 \% \text { water } \\
\text { in glycerol }\end{array}$ & $\begin{array}{l}1: 3.2 \text { molar } \\
(1: 0.43 \text { mass })\end{array}$ & 2 & 4.6 & 240 & $56 \mathrm{MG}, 6.9-12.7$ FFA & 16 \\
\hline $\begin{array}{l}\text { Soybean, } \\
\text { peanut, } \\
\text { cottonseed, } \\
\text { corn, canola }\end{array}$ & $\begin{array}{l}\mathrm{CO}_{2} / 4 \% \text { water } \\
\text { in glycerol }\end{array}$ & $1: 25$ molar & 4 & 20.7 & 250 & $\begin{array}{l}\text { 41.1-49.2 MG, 26.6-35.0 DG, } \\
\text { 10.1-16.0 TG, 8.8-14.0 FFA }\end{array}$ & 5 \\
\hline Soybean & $\begin{array}{l}\mathrm{CO}_{2} / 4 \% \text { water } \\
\text { in glycerol }\end{array}$ & $1: 25$ molar & 4 & 20.7 & 250 & - & 17 \\
\hline Canola & $\begin{array}{l}\mathrm{CO}_{2} / \mathrm{N}_{2} 8 \% \text { water } \\
\text { in glycerol }\end{array}$ & $1: 34$ molar & $9-10$ & $10-20$ & 250 & $\begin{array}{l}\text { MG }(66-71), \text { DG }(13-15), \\
\text { TG }(0-1), \text { FFA }(13-17)\end{array}$ & 1 \\
\hline \multirow[t]{3}{*}{ Sunflower } & $\begin{array}{l}\text { Acetone } 1: 1 \mathrm{~mL} \mathrm{~g}^{-1} \\
\text { glycerol }\end{array}$ & $\begin{array}{l}1: 5 \text { molar } \\
(1: 0.53 \text { mass })\end{array}$ & 2 & $1.5-1.8$ & 250 & $\begin{array}{l}\text { 52.0 MG (63.3), 35.6 DG (25.6), } \\
\text { 7.1 TG }(4.5), 6.3 \text { FFA (9.6) }\end{array}$ & This study \\
\hline & $\begin{array}{l}\text { Acetone } 1: 1 \mathrm{~mL} \mathrm{~g}^{-1} \\
\text { glycerol }\end{array}$ & $\begin{array}{l}1: 5 \text { molar } \\
(1: 0.53 \text { mass })\end{array}$ & 1 & $1.5-1.8$ & 250 & $\begin{array}{l}\text { 44.1 MG (54.9), 44.1 DG } \\
(31.6), 13.9 \text { TG }(7.0), 4.1 \text { FFA }(6.5)\end{array}$ & This study \\
\hline & $\begin{array}{l}\text { Acetone } 1: 1 \mathrm{~mL} \mathrm{~g}^{-1} \\
\text { glycerol, } 10 \% \text { water } \\
\text { in glycerol }\end{array}$ & $\begin{array}{l}1: 5 \text { molar } \\
(1: 0.53 \text { mass })\end{array}$ & 1 & $1.5-1.8$ & 250 & $\begin{array}{l}\text { 43.3 MG (53.5), 34.4 DG }(24.4) \\
\text { 12.2 TG }(6.1), 10.3 \text { FFA }(16.1)\end{array}$ & This study \\
\hline
\end{tabular}


those reported in literatures except that in the process proposed in this study solketal was co-produced.

In this study even at high reactor loading $(\sim 80 \%)$ and excess acetone addition $(50 \mathrm{~mL})$, the highest pressure achieved was only about $3.5 \mathrm{MPa}$. This is considerably lower than pressure required $(>10 \mathrm{MPa})$ in most studies using carbon dioxide or nitrogen to pressurize the reactor and utilizing only $33 \%$ of the reactor volume..$^{1,5,17}$

In previous studies water was required which acted as catalyst or aided the reaction by partially hydrolyzing oils. Addition of $10 \%$ water was also tested in this study, which resulted in higher FFA and lower DG contents in the product. Although the amount of DG was lower than that without addition of water, the amount of MG produced is still acceptable ( $43 \mathrm{wt} \%$ or $53.5 \mathrm{~mol} \%$ ), which is similar to those reported in literatures. Nevertheless method proposed in this study allows the production of PGs in a much shorter time without the use of catalyst. Acetone can be easily removed by depressurizing the reactor at the end of the reaction. Moreover the use of acetone produces solketal which is a fuel additive and has applications in pharmaceutical preparation, can be used as a solvent, a plasticizer and a suspension agent. ${ }^{15}$ Although the amount of solketal produced was only $4.5 \%$, this is the first study to report the co-production of solketal during glycerolysis of oil. In view of later industrialization the recovery of solketal would not result in additional processing cost. This is due to its lower boiling point $\left(188^{\circ} \mathrm{C}\right)$ than that of partial glycerides, allowing it to be recovered in the purification of partial glycerides.

\section{Conclusion}

Acetone has been shown as an effective solvent for the glycerolysis of oil to produce PGs. Apart from acting as a solvent, at temperatures beyond its critical temperature acetone may also act as an acid catalyst. Moreover with the use of acetone solketal was produced as a byproduct. The use of acetone in glycerolysis of oil allowed the production of PGs at $250{ }^{\circ} \mathrm{C}$ and 1.8 MPa in $2 \mathrm{~h}$ with a product composition of $4.5 \%$ solketal, $5.8 \%$ FFA, $49.2 \%$ MG, 33.5\% DG and 7\% TG. Other important parameters realized in this study are stirring and reactor loading.

\section{Conflict of interest}

The authors declare no conflict of interest regarding this work.

\section{Abbreviations}

$\begin{array}{ll}\text { AG } & \text { Acylglyceride } \\ \text { MG } & \text { Monoglycerides } \\ \text { DG } & \text { Diglycerides } \\ \text { PG } & \text { Partial glycerides } \\ \text { FFA } & \text { Free fatty acid } \\ \text { HTGC } & \text { High temperature gas chromatography }\end{array}$

\section{Acknowledgements}

The authors would like to acknowledge the financial supports of the Ministry of Science and Technology of Taiwan (NSC 1022221-E-011-079) and National Taiwan University of Science and Technology (103M47006).

\section{References}

1 P. H. L. Moquin, F. Temelli, H. Sovova and M. D. A. Saldana, Kinetic modeling of glycerolysis-hydrolysis of canola oil supercritical carbon dioxide media using equilibrium data, J. Supercrit. Fluids, 2006, 37, 417-424.

2 P. Chetpattananondh and C. Tongurai, Synthesis of high purity monoglycerides from crude glycerol and palm stearin, Songklanakarin J. Sci. Technol., 2008, 30(4), 515-521.

3 Y. C. Yang, S. R. Vali and Y. H. Ju, A process for synthesizing high purity monoglyceride, J. Chin. Inst. Chem. Eng., 2003, 34, 617-623.

4 N. O. V. Sonntang, Glycerolysis of fats and methyl estersstatus, review and critique, J. Am. Oil Chem. Soc., 1982, 59, 795-802.

5 F. Temelli, J. W. King and G. R. List, Conversion of oils to monoglycerides by glycerolysis in supercritical carbon dioxide media, J. Am. Oil Chem. Soc., 1996, 73, 699-706.

6 D. A. Echeverri, F. Cardeno and L. A. Rios, Glycerolysis of soybean oil with crude glycerol containing residual alkaline catalyst from biodiesel production, J. Am. Oil Chem. Soc., 2011, 88, 551-557.

7 D. A. Echeverri, F. Cardeno and L. A. Rios, Glycerolysis of crude methyl ester with crude glycerol containing residual alkaline catalyst from biodiesel production, J. Am. Oil Chem. Soc., 2013, 90, 1041-1047.

$8 \mathrm{H}$. Noureddini and V. Medikonduru, Glycerolysis of Fat and Methyl Esters, J. Am. Oil Chem. Soc., 1997, 74, 419-425.

9 D. S. Negi, F. Sobotka, T. Kimmel, G. Wozny and R. Schomacker, Glycerolysis of fatty acid methyl esters: 1. Investigations in a batch reactor, J. Am. Oil Chem. Soc., 2007, 84, 83-90.

10 K. G. Fiametti, M. K. Ustra, D. Oliveria, M. L. Corazza and A. Furigo, et al., Kinetics of ultrasound-assisted lipase catalyzed glycerolysis of olive oil in solvent-free system, Ultrason. Sonochem., 2012, 19, 440-451.

11 T. Yang, M. Rebsdorf, U. Engelrud and X. B. Xu, Enzymatic production of monoacylglycerols containing polyunsaturated fatty acids through an efficient glycerolysis system, J. Agric. Food Chem., 2005, 73-79.

12 G. Aw, S. Sutanto, B. T. Nguyen Thi, L. L. Cabatingan, S. Ismadji and Y. H. Ju, Transesterification of soybean oil with methanol and acetic acid at lower reaction severity under subcritical conditions, Energy Convers. Manage., 2014, 88, 1159-1166.

13 J. L. Zheng, X. D. Wang, B. Zhao, J. C. Sun and Y. C. Wang, Rapid In Situ Transesterification of Sunflower Oil, Ind. Eng. Chem. Res., 2009, 48, 850-856. 
14 N. J. Zhong, L. Li, X. B. Xu, L. Z. Cheong, Z. H. Zhao and B. Li, Production of diacyl glycerols through low-temperature chemical glycerolysis, Food Chem., 2010, 122, 228-232.

15 D. Royon, S. Locatelli and E. E. Gonzo, Ketalyzation of glycerol to solketal in supercritical acetone, J. Supercrit. Fluids, 2011, 58, 88-92.
16 M. H. Itiner, US Pat. 2,474,740, 1949.

17 P. H. L. Moquin, F. Temelli, J. W. King and M. M. Palcic, Kinetic modelling of the glycerolysis reaction for soybean oils in supercritical carbon dioxide media, J. Am. Oil Chem. Soc., 2005, 82, 613-617. 